A Cascading Approach to Training Discovery

\title{
A Cascading Approach to Training Discovery
}

Submission Date: September 13, 2018

Revisions Submitted: December 3, 2018

Final Copy Submitted: January 7, 2019 
A Cascading Approach to Training Discovery
ABSTRACT
- Purpose
- The purpose of this paper is to illustrate why libraries should develop instructional plans to further integrate Web-scale discovery services into the academy, as well as propose a three-fold delivery plan to achieve this goal.

- Design/methodology/approach

- This paper documents a strategy to integrate Web-scale discovery services into library training and instruction for multiple audiences. The strategy is informed by past analysis of discovery service search queries.

- Findings

- It presents a three-part training plan that can be applied to multiple audiences, universities/colleges, and even discovery service platforms.

- Practical implications

- The strategies and practices detailed in this paper are easily adaptable to other institutions that currently subscribe to Web-scale discovery service products.

- Originality/value

- This paper introduces an innovative approach toward transforming Web-scale discovery instruction across the academy, based on search query analysis.

\section{KEYWORDS}

Discovery Services, Academic Libraries, Outreach, Instruction, Training, Student Employees

\section{TYPE}

Case Study 


\section{A Cascading Approach to Training Discovery}

\section{INTRODUCTION}

As libraries acquired Web-scale discovery services over the past 10 years, many librarians also began to promote these tools as one-stop research shops: if you need academic resources and don't know what to do or where to go, start here. A problem has emerged with this approach in that, by and large, librarians assumed these tools were straightforward and intuitive to all users and thus, for the most part, did not develop detailed training programs for these resources. As it turns out, despite abundant search figures, not all users know how to use discovery services, and many users are not using these tools effectively.

In this paper, librarians from Indiana University (IU) Bloomington and Indiana University (IU) Kokomo present a cascading training approach for Web-scale discovery services. The researchers recognized a need for a training program after evaluating and categorizing search query data from two campus discovery services. This project produced two primary revelations: 1) Discovery service use is voluminous; and 2) Many queries revealed deficiencies in basic, let alone advanced, searching techniques. These results exposed an obvious need to reevaluate instructional strategies for discovery services. That is, while a single point of entry helped to reduce confusion about where to begin research, it had not resolved the question of how to do research.

To solve this problem, the authors developed a three-part plan to approach Web-scale discovery service training. This article explains the plan in order to introduce a new way to use discovery service data outside of demonstrating the value of library subscriptions. The plan described within this article is not a discovery service promotional campaign. Rather, it is a purposeful program to develop instructional services among librarians and library staff, library student employees, and teaching faculty. The authors propose that the plan, in part or in whole, can be implemented at institutions of various sizes with various audiences, and even with different discovery service platforms. The intent of this article is to initiate a 


\section{A Cascading Approach to Training Discovery}

conversation within the library and information sciences professional community regarding how to use discovery service data and improve users' understandings of these powerful yet complex tools.

\section{LITERATURE REVIEW}

The plan described in this article builds upon literature about the adoption and use of Web-scale discovery services, general training strategies and priorities for librarians and library staff, and opportunities to use search query data to improve outreach and instruction. As Web-scale discovery enters its relative adolescence, librarians have the opportunity, if not the obligation, to reevaluate and revitalize the ways in which these products are taught in staff development, at the reference desk, and in the classroom. Librarians have previously emphasized the need to familiarize reference and instruction librarians with discovery tools in order to reach and teach library users (Kornblau et al., 2012). Yet, as Fawley and Kyrsak (2014, p. 284) note, librarians in these roles "remain divided in their support for and use of these tools." Seeber (2015, p. 21-22) effectively details research on librarian feelings toward discovery and points out the conundrum: "So, while more and more institutions are adopting discovery platforms, and search log analyses reveal that students are poor at using these tools, much of the literature shows that librarians are not necessarily committed to Web-scale discovery, and often choose not to teach these platforms to their students." Further, as Foster (2018) found in a survey of public service librarians, even those who recommend Web-scale discovery services to students do not themselves use the services for their own research. Such reports indicate that perhaps the initial discovery familiarization process was incomplete, unsuccessful, or too distant in the past to affect current attitudes and practices.

Recommendations for training reference staff, whether students, paraprofessionals, or librarians, consistently endorse continued development, particularly for advances in available and widely used technology (Courtney and Courtney, 2015; Woodard, 2016). Training for student employees often 


\section{A Cascading Approach to Training Discovery}

involves shadowing librarians, as well as completing self-guided tutorials (Gonnerman and Johnson, 2016; Manley and Holley, 2014). Faix (2014) describes a more thorough training process, including ongoing weekly tutorials on the library catalog, subject-specific databases, and reference interview techniques. Training that extends beyond the first period of employment, whether for students or other library staff, creates more opportunities to learn about new features of existing platforms or tools or even entirely new resources.

Colbert-Lewis et al. (2015, p.186) summarize: "In order to remain professionally relevant, librarians must have a comfort zone in working with current technologies while having a willingness to learn and keep abreast of emerging trends." Rather than expecting instruction and reference librarians and staff to develop these skills solely through their own self-directed continuing education, systems and other technical services librarians can implement and share their in-depth knowledge of Web-scale discovery services, including search query data. This training, such as the plan developed and proposed by the authors, would not only improve the services provided to library users at the reference desk and in the classroom, but it would also encourage recognition of the unique contributions made by technical services librarians (Weng and Ackerman, 2017).

Structured, purposeful training on Web-scale discovery services for fellow librarians further expands the impact that systems and technical services librarians can have on shaping information literacy instruction. Systems librarians already, as described by Cowan (2014), "do" information literacy by selecting and maintaining Web-scale discovery services, among many other library resources, tools, and platforms. Beyond this, systems librarians can provide data and strategies to reach students where they are: searching via discovery. The significance of this contribution is unmistakable, as the majority of information literacy instruction currently centers on information evaluation and research strategies (Julien et al., 2018). Similarly, as reference interactions are increasingly viewed as opportunities for microteaching 


\title{
A Cascading Approach to Training Discovery
}

(Rutledge and LeMire, 2017), training on how and when to use discovery services can broadly affect the quality of information literacy instruction wherever it occurs.

\begin{abstract}
A key step toward the purposeful integration of a training plan is engagement with teaching faculty. In recent explorations of student help-seeking practices, librarians have grappled with users who are unlikely to seek out their assistance with research. Apart from their peers, students most frequently approach their professors. Explanations and speculations for this are numerous, notably including familiarity, perceived efficiency, and assumed subject-matter expertise (Thomas et al., 2017; Vinyard et al., 2017). Therefore, it is critical that librarians develop relationships and collaborate with teaching faculty in order to reach students. Librarians have documented numerous successful outreach and partnership efforts with faculty in varied applications, including liaison work (Díaz and Mandernach, 2017), train-the-trainer models (Gilman et al., 2017), and participating in digital research projects (Courtney and Courtney, 2015).
\end{abstract}

Web-scale discovery service search query data present a new and promising avenue for faculty collaboration. As emphasized by Díaz and Mandernach (2017, p. 277), relationships between faculty and librarians are at their strongest "when librarians push boundaries and go beyond the expectation of suggesting services and sources.” Although librarians have used search query data to understand user behavior and redesign website interfaces (Ndumbaro, 2018; Brett, German, and Young, 2015; Chapman et al., 2013), this data has been under-utilized for developing instruction and reference services. A handful of libraries have explored why users' search queries may fail in discovery services. Unsuccessful queries were primarily attributed to the library not possessing the desired material, the item not being indexed within the discovery system, or the query being ambiguous or not understandable, such as due to a misspelling, incorrect publication year, or other citation error (Behnert and Lewandoski, 2017, p. 132; Huurdeman, Aamodt, and Heggø, 2018, p. 30). These studies concentrated on technological solutions to improve users' search experiences, including improved spelling suggestions, partial keyword matching strategies, and automated links to help forms or services. Huurdeman et al. (2018, p. 32) touch upon 


\section{A Cascading Approach to Training Discovery}

human involvement in improving users' search queries: "It is important to emphasize to end-users that they may have to put more effort in actually receiving the 'right' materials."

The plan described herein addresses how to improve user behavior within discovery systems through nontechnical solutions, an area that requires further exploration. Dempsey and Valenti (2016) centered their investigation of student search histories within a Web-scale discovery service around library engagement. Their study looked into whether students used database limiters and whether their keyword selections were effective, following library instruction. The study was limited to 118 students enrolled in a single introductory English course, though, and the data was collected during actual instruction sessions, when librarians could provide assistance. With that said, Dempsey and Valenti open the possibility of using discovery search data to move beyond technological recommendations in order to improve library instruction. In this paper, the authors propose a plan to use discovery service search query data as thought-provoking conversation starters with librarians, library staff, student employees, and faculty. In addition to focusing on training and instruction initiatives versus technology-based improvements, this plan is unique in that it presents the approach upfront, prior to implementation. The rationale for sharing the plan in advance is to declare the authors' intentions and invite the community into our exploratory conversations.

\section{BACKGROUND}

Prior to developing the training approach described herein, the authors devoted significant time and consideration to their institutions' current usage of Web-scale discovery and existing training procedures. IU Bloomington, the flagship campus of Indiana University, enrolled nearly 40,189 FTE students in fall 2017, whereas IU Kokomo, a regional campus of IU, enrolled approximately 2,492 FTE students during this term[i]. Both campuses implemented EBSCO Discovery Service (EDS) in fall 2011. Despite their 


\section{A Cascading Approach to Training Discovery}

drastic size differences in student populations, the authors recognized similar issues in terms of library staff and faculty instruction/training on their respective discovery services.

\section{Librarian and Library Staff Training}

Librarians at IU Kokomo, regardless of their role, contribute to reference services by staffing the Research Help Desk and answering in-person, phone, email, and chat reference questions. Evening reference services are largely supported by part-time library staff. IU Bloomington, on the other hand, does not require all librarians to staff the main library's reference desk. Public service librarians, including some subject specialists, and a few Professional Staff work the various reference desks, but staffing largely depends on individual departmental staffing allocations, the expectations of supervisors or Associate Deans, and employee workloads. During the 2017-2018 academic year, for example, only one IU Bloomington librarian from the Teaching and Learning department had a regular desk shift, only three branch librarians had regular desk shifts, and none of the Area Studies librarians had reference shifts. However, these librarians did answer referred reference questions and served as substitutes at the desk, if needed. That being said, the fact remains that the majority of the IU Bloomington librarians who teach and work with other teaching faculty do not staff the reference desk.

At both campuses, reference training focuses largely on procedural practices - such as how to log in to systems and record questions - and reference skills are expected to be previously developed or selftaught. Importantly, if a new librarian at IU Bloomington arrives from another university that either did not have a discovery service or did not have EDS in particular, he or she does not receive any formal training on how or when to use it. There is a similar, nominal approach at IU Kokomo. 


\section{A Cascading Approach to Training Discovery}

The librarians and staff at both campuses have varying levels of familiarity with and affinity for EDS. Librarians who refer to EDS as "the" starting point for most research questions will, at times, be corrected by others who instead prefer EDS to be promoted as "a" starting point for most research questions. The difference in approaches is simultaneously minor and significant: while both clearly indicate that EDS is useful, one approach demonstrates a much higher valuation of the discovery service. As such, students and other users who approach the Research Help Desk on two consecutive days, when two different librarians staff the desk, will likely receive divergent starting points. This experience can lead to confusion or wariness for the user. More consistent training on EDS among librarians and staff will lead to a more consistent experience for those who use reference services.

\section{Student Employee Training (undergraduate and graduate)}

Student employees at IU Kokomo and IU Bloomington are trained to answer circulation, specific search, and basic reference questions. While student employees are still expected to refer complex research questions to librarians, they are encouraged to assist users with research starting points, especially EDS and the library catalog. Their familiarity with these platforms and their comfort levels assisting with basic reference questions are particularly important during weekends and evenings, when they are often the only scheduled staff.

Notably, training for student employees is more deliberate and extensive than training for librarians and professional staff. At IU Kokomo, student employees attend an in-person, one-day training session prior to the beginning of each fall semester, and, as of 2017, participate in continuing education throughout the academic year. Ongoing student staff development includes online quizzes, known as "research challenges", which are created and administered on Springshare's LibWizard platform (see Appendix). Student employees' performance in these challenges then shapes in-person, two- or three-hour training sessions. Topics previously covered in challenges and trainings include EDS, the library catalog, and 


\section{A Cascading Approach to Training Discovery}

library website navigation, including locating and selecting databases. Student employees are asked to identify opportunities to use EDS and describe search strategies that they would recommend to users, namely generating related search terms and using limiters. This focused approach to training student employees conspicuously reinforces the assumption that all student employees require training on library tools and platforms, including Web-scale discovery services, but that librarians and other library staff do not.

At IU Bloomington, student employees attend a training meeting prior to their first shift at the reference desk and then continue to attend weekly meetings throughout each semester. Most of the training does not focus on specific databases or features; instead, student employees work on reference interview techniques, chat processes, and other desk procedures. If a particular database is covered, it is usually in the context of providing reference services for a particular subject, or it is lumped together with several other topics. For example, in 2017, a discussion of EDS was included in a 30-minute talk about the library catalog, EDS, and Electronic Resource troubleshooting.

\section{Library Instruction and Outreach}

Library instruction at IU Kokomo focuses on face-to-face introductory writing and speech courses. These courses are often taught by adjunct faculty who are either encouraged or required by their program coordinators to schedule one-shot library instruction sessions. These sessions serve to both expose students to library services and resources, as well as aid in achieving information literacy learning outcomes as defined by the campus' general education program. Instruction at IU Bloomington is mostly entrusted to subject librarians and can vary from department to department. Thus, there is currently no unified outreach program in terms of teaching library resources or research skills. 


\section{A Cascading Approach to Training Discovery}

Although training and outreach initiatives at IU Bloomington and IU Kokomo vary, actual user behavior at the campuses is more alike than it is different. In two separate studies, researchers compared EDS usage data across campuses and found many parallels. For instance, the majority of EDS usage at two institutions occurred on desktop computers during the 2013-2014 academic year (Cohen and Thorpe, 2015). Additionally, approximately the same percentage (6.1\%) of searches at both institutions used field codes to narrow the size of result sets. In a subsequent study, researchers compared and scrutinized the content of anonymous EDS search queries recorded during the fall 2015 semester (Cohen and Thorpe Pusnik, 2018). Random samples of search queries from both campuses were categorized using the Library of Congress classification system. Queries from the Social Sciences class appeared most often at both campuses, and the majority of searches were Basic, not Advanced. These studies demonstrate ample need for more instruction and outreach to students and faculty in order to improve discovery service search skills.

\section{THE APPROACH}

Over the course of nearly four years, IU Bloomington and IU Kokomo have gathered a great deal of data about how their discovery services are being used. The next step, then, is to put this data into use. In this three-part, cascading approach, specific audiences are trained on Web-scale discovery in an order that maximizes impact. The plan described below will be implemented in fall 2018.

\section{Part 1: Communication and Training for Librarians and Library Staff}

The first part of the cascading plan focuses on communication and training for librarians and library staff. A major part of this plan is the creation of an internal communication plan, created for both public services librarians and those "behind-the-scenes" librarians such as collection managers, subject 


\section{A Cascading Approach to Training Discovery}

specialists, systems librarians, and/or technical services librarians. Timely updates and announcements, instructional materials, and supplementary resources will serve as continuous education on Web-scale discovery services for all library staff, including - notably - reference and other public services librarians who may be resistant to, or who may simply not have the time to devote to, more structured training.

Maintaining a communication channel can be problematic for an organization of any size but is especially difficult for larger institutions. The IU Bloomington Libraries, for example, employ more than 580 employees $^{1}$ throughout its 15 libraries. Of course, communication issues are not limited to large organizations. The smaller staff size at IU Kokomo means that each librarian is responsible for an everincreasing number of service areas and duties, making focused attention and communication on any single topic challenging. One solution is to create and maintain an internal blog, wiki, LibGuide, or other document, that can be quickly updated and easily accessed at point-of-need by any library staff ${ }^{2}$.

To this end, behind-the-scenes librarians will create and maintain an EDS communication portal which contains:

- A running list of both implemented and forthcoming updates;

- Known bugs, any workarounds, and, if available, time estimates for resolutions;

- Announcements for bug fixes;

- An updated list of all databases - including full text, open access, and abstract-only - that are included in the discovery service index;

\footnotetext{
${ }^{1}$ This number includes Tenure-track Librarians, Professional Staff, Support Staff, and Temporary (student) employees.

${ }^{2}$ In 2017, Indiana University as a whole purchased EDS for all campuses. While each campus runs/supports their own version of EDS, the campuses do share a catalog extract and try to share information about upcoming changes, bugs, etc. Having a communication plan for the entire system would allow the university to share information more consistently, as well as push for enhancements as a collective, which would provide more bargaining power than any requests submitted by a single campus.
} 


\title{
A Cascading Approach to Training Discovery
}

- A current list of databases with custom links from the discovery service to full text content;

- Training documents for instruction/reference sessions; and

- Contact information for system administrators in order to submit bugs, ask questions, or make recommendations.

\begin{abstract}
The inclusion of announcements about platform updates, bugs, and fixes is an important incentive for librarians who staff the reference desk, as this context will facilitate their efforts to provide quality service to users. Since moving from no training to intensive training on Web-scale discovery services may be too seismic a shift, this "build it and they will come" approach will likely be better received by librarians with reference and instruction responsibilities. The goal of the internal guide is to spur library staff and empower them to learn about the discovery service, thereby increasing their comfort working with the discovery tool while minimizing their frustration and confusion. If staff are receptive to this initial guide, additional training strategies - such as videos, modules, or workshops - may be incorporated later on. This communication plan can be adapted and implemented by an organization of any size, with any discovery system.
\end{abstract}

Part 2: Communication and Training for Student Employees (undergraduate and graduate)

The second part of the cascading approach focuses on student staff training. IU Kokomo plans to expand its recently-developed continuing education for student employees. With an emphasis on creating training that is both engaging and interactive, the program prioritizes role-playing exercises, team competitions, and research challenges. These activities are rooted in both EDS search query data and questions recorded at library service desks. Previous training activities indicate that student employees most struggle with where to first direct users with basic research questions, especially when presented with the wide variety of tools and platforms available through the library website. 


\section{A Cascading Approach to Training Discovery}

Discussions have also been held at IU Bloomington regarding creating a more cohesive training plan for all Research Assistants across the campus libraries. Currently, each library individually manages hiring and training its student employees. Consequently, the training can vary widely depending on the desk at which the student works. At present, some key vacant positions need to be filled at IU Bloomington before this cohesive, cross-campus training can transpire. In the meantime, librarians are advocating for more training on EDS for students who work the reference desk at the main library on campus, hoping to later expand to other campus libraries. Working in collaboration with the coordinator for student employees, the plan is to create independent exercises for students, asynchronous training presentations, and in-person training sessions that will address questions and answers from the student employees.

The authors anticipate that additional, more purposeful training on EDS will grow student staff confidence in directing users to the discovery service, as well as in developing basic search strategies. While student staff will not be expected to provide the in-depth research services that librarians provide at the various reference desks, student staff should feel empowered to pursue their own research and provide quality guidance to users.

\section{Part 3: Instruction and Outreach}

For the third piece of the cascading project plan, librarians must enthusiastically take the lead in educating our teaching faculty about current resources available through the library. EDS search query data provide a great opportunity to demonstrate to faculty that their students, whether instructed or required to or not, are already using Web-scale discovery, thus making it a relevant topic for library instruction.

IU Kokomo librarians plan to schedule consultations with teaching faculty, particularly those who teach research-intensive courses, in which EDS search query data can be shared and discussed. The purpose of 


\title{
A Cascading Approach to Training Discovery
}

these conversations will not be to immediately promote EDS or prescribe a certain instructional program. Rather, the purpose will be to initiate conversations about how faculty and students in specific departments are using library services - based on collected data - and how the faculty members would ideally like to collaborate with the library. This approach hints at Seeber's "format as a process" framework in which librarians discuss the research process, not specific resource formats or locations, in instruction sessions (p. 24). The authors will use discovery service search query data that illustrate actual user search processes to augment this model. Focusing the conversation on students' search strategies can create a low-stakes opportunity to teach faculty about Web-scale discovery services. This fulfills the charge set forth by Eva (2015) to market our expertise, both as librarians and academics, to faculty.

Additionally, to reach graduate and undergraduate students at a larger scale, librarians at IU Bloomington will design general EDS resources, including brief tutorials and quick guides on basic search functions (see image 1). These learning objects will serve as a starting point to collaborate more deeply and intentionally with teaching faculty. That is, librarians will gather faculty feedback on general resources and incorporate their comments into new, discipline- or assignment-specific instructional materials that can be used in face-to-face and/or online services. These materials will improve awareness of how librarians can partner with faculty to develop students' research skills.

\section{INSERT IMAGE 1}

\section{CONCLUSION}

\author{
Regardless of librarians' varied approaches and responses to Web-scale discovery services, usage reports \\ demonstrate that students, faculty, and staff are using these tools, and search query data indicate usage is
}




\section{A Cascading Approach to Training Discovery}

multi- and interdisciplinary. As libraries then move beyond the goal of mere promotion, librarians must develop and implement a plan to train students and faculty on how and when to effectively use a discovery service. However, before training users, librarians must first collaborate across public and technical services roles and train one another on the features and functions of Web-scale discovery services. Doing so will empower all librarians and library staff to teach search strategies for discovery in student employee training, at the reference desk, and in the classroom. A keener familiarity with Webscale discovery, including awareness of search query data, will engender confidence when librarians and library staff direct students to this tool, as well as when they discuss with faculty how the tool can support research goals.

The authors suggest that the three-part plan described in this paper can serve as a model for training Webscale discovery at institutions of various sizes, with various audiences, and even with different Web-scale discovery services. In approaching Web-scale discovery as a service that must be taught in order to be used effectively, this plan affirms the role of the librarian as instructor and collaborator, both within the library and across the institution. Some future goals for continuing and enhancing this plan include: gathering feedback from librarians and library staff, including student employees, on their current use of Web-scale discovery and the areas in which they require supplemental training, following initial efforts; further defining and expanding faculty outreach; and updating search query data analyses to identify additional search trends and areas for growth. Ongoing conversations about how discovery service usage data can be used in order to improve users' information literacy skills within these robust tools are also necessary for library service development.

\section{NOTES}

i. IU FTE reporting can be found at:

https://tableau.bi.iu.edu/t/prd/views/uirr_sr_est_official_enrollment_public/HeadsandHours?\%3Aembed= 
A Cascading Approach to Training Discovery

$\mathrm{y} \& \% 3$ AshowShareOptions $=$ true $\& \% 3$ Adisplay count $=$ no $\& \% 3$ AshowVizHome $=$ no (accessed 3 January 2019)

\section{REFERENCES}

Behnert, C. and Lewandowski, D. (2017), "Known-item searches resulting in zero hits: Considerations for discovery systems", The Journal of Academic Librarianship, Vol. 43 No. 2, pp. 128-134.

Brett, K., German, E., and Young, F. (2015), “Tabs and Tabulations: Results of a Transaction Log Analysis of a Tabbed-Search Interface", Journal of Web Librarianship, Vol. 9 No. 1, pp. 22-41.

Chapman, S., Desai, S., Hagedorn, K., Varnum, K., Mishra, S., and Piacentine, J. (2013), "Manually Classifying User Search Queries on an Academic Library Web Site", Journal of Web Librarianship, Vol. 7 No. 4, pp. 401-421.

Cohen, R. and Thorpe, A. (2015). "Discovering user behavior: Applying usage statistics to shape frontline services", The Serials Librarian, Vol. 69 No. 1, pp. 29-46.

Cohen, R. and Thorpe Pusnik, A. (2018), “Applying data analysis: Demonstrate value, shape services, and broaden information literacy", Against the Grain, Vol. 30 No. 1, pp.67-68.

Cohen, R.A. and Thorpe Pusnik, A. (2018), "Measuring query complexity in Web-scale discovery: A comparison between two academic libraries", Reference \& User Services Quarterly, Vol. 57 No. 4, pp. 274-284.

Colbert-Lewis, D., Scott-Branch, J. and Rachlin, D. (2015), "Necessities of Librarianship: Competencies for a New Generation", in Forbes, C. and Bowers, J. (Eds.), Rethinking Reference for Academic Libraries, Rowman \& Littlefield, London, UK, pp. 185-199.

Courtney, M. and Courtney, A. (2015), “Step Away from the Desk: Partnerships for Lifelong Learning”, in Forbes, C. and Bowers, J. (Eds.), Rethinking Reference for Academic Libraries, Rowman \& Littlefield, London, UK, pp. 3-15. 
A Cascading Approach to Training Discovery

Cowan, S.M. (2014), “Information Literacy: The Battle We Won That We Lost?”, portal: Libraries and the Academy, Vol. 14 No. 1, pp. 23-32.

Dempsey, M. and Valenti, A.M. (2016), "Student Use of Keywords and Limiters in Web-scale Discovery Searching", The Journal of Academic Librarianship, Vol. 42 No. 3, pp. 200-206.

Díaz, J.O. and Mandernach, M.A. (2017), "Relationship Building One Step at a Time: Case Studies of Successful Faculty-Librarian Partnerships”, portal: Libraries and the Academy, Vol. 17 No. 2, pp. $273-282$.

Eva, N. (2015), “Marketing to Faculty in an Academic Library”, Reference \& User Services Quarterly, Vol. 54 No. 4, pp. 26-28.

Faix, A. (2014), "Peer reference revisited: Evolution of a Peer-Reference Model”, Reference Services Review, Vol. 42 No. 2, pp. 305-319.

Fawley, N. and Krysak, N. (2014), "Learning to Love your Discovery Tool: Strategies for Integrating a Discovery Tool in Face-to-Face, Synchronous, and Asynchronous Instruction", Public Services Quarterly, Vol. 10, pp. 283-301.

Foster, A.K. (2018), "Determining Librarian Research Preferences: A Comparison Survey of Web-scale Discovery Systems and Subject Databases”, The Journal of Academic Librarianship, Vol. 44 No. 3, pp. 330-336.

Gilman, N.V., Sagas, J., Camper, M. and Norton, A.P. (2017), “A Faculty-Librarian Collaboration Success Story: Implementing a Teach-the-Teacher Library and Information Literacy Instruction Model in a First-Year Agricultural Science Course", Library Trends, Vol. 65 No. 3, pp. 339-358.

Gonnerman, K. and Johnson, K. (2016), "Peer reference assistants in a small liberal arts college: case study", Reference Services Review, Vol. 44 No. 3, pp. 292-308.

Huurdeman, H.C., Aamodt, M., and Heggø, D.M. (2018), "More than Meets the Eye-Analysing the Success of User Queries in a Library Discovery System", Nordic Journal of Information Literacy in Higher Education, Vol. 10 No. 1, pp. 18-36. 
A Cascading Approach to Training Discovery

Julien, H., Gross, M. and Latham, D. (2018), “Survey of Information Literacy Instructional Practices in U.S. Academic Libraries”, College \& Research Libraries, Vol. 79 No. 2, pp. 179-199.

Kornblau, A.I., Strudwick, J. and Miller, W. (2012), "How Web-scale Discovery Changes the Conversation: The Questions Librarians Should Ask Themselves", College \& Undergraduate Libraries, Vol. 19 No. 2-4, pp. 144-162.

Manley, L. and Holley, R.P. (2014), "Hiring and Training Work-Study Students: A Case Study”, College \& Undergraduate Libraries, Vol. 21 No. 1, pp. 76-89.

Ndumbaro, F. (2018), “Understanding Use-System Interactions: An Analysis of OPAC Users’ Digital Footprints", Information Development, Vol. 34 No. 3, pp. 297-308.

Rutledge, L. and LeMire, S. (2017), "Broadening Boundaries: Opportunities for Information Literacy Instruction inside and outside the Classroom”, portal: Libraries and the Academy, Vol. 17 No. 2, pp. 347-362.

Seeber, K.P. (2015), “Teaching 'Format as a Process' in an Era of Web-scale Discovery”, Reference Services Review, Vol. 43 No. 1, pp. 19-30.

Thomas, S., Tewell, E. and Wilson, G. (2017), "Where Students Start and What They Do When They Get Stuck: A Qualitative Inquiry into Academic Information-Seeking and Help-Seeking Practices”, The Journal of Academic Librarianship, Vol. 43, pp. 224-231.

Vinyard, M., Mullally, C. and Colvin, J.B. (2017), "Why do Students Seek Help in an Age of DIY? Using a Qualitative Approach to Look Beyond Statistics”, Reference \& User Services Quarterly, Vol. 56 No. 4, pp. 257-267.

Weng, C. and Ackerman, A. (2017), “Towards Sustainable Partnership: Examining Cross Perceptions of Public and Technical Services Academic Librarians”, LRTS, Vol. 61 No. 4, pp. 198-211.

Woodard, B.S. (2016), “Training and Continual Learning for Reference Staff”, in Smith, L.C. and Wong, M.A. (Eds.), Reference and Information Services: An Introduction, ABC-CLIO, Santa Barbara, CA, pp. 240-280. 
A Cascading Approach to Training Discovery

\author{
APPENDIX \\ your search?
a. Databases by Subject
b. EDS
c. Online library catalog
d. Google Scholar
e. Journal Finder

Student Employee Training - Fall 2017 Research Challenge 1 questions

1. A student is looking for a book on her paper about gay rights and adoption. Where do you start

2. A student wants to check out the book Nursing ethics and professional responsibility in advanced practice. Do we own this book?
a. Yes, they can check out this book from the stacks
b. Yes, they can read it as an ebook
c. No, but a different university campus does own this book
d. No, they will need to request it from interlibrary loan
e. No, they will need to request it from the statewide circulation system

3. A student was told to use CINAHL for their project. What is the best way to direct them to this resource?
a. Databases A-Z
b. Online library catalog
c. EDS
d. Journal Finder
e. "Find" menu 


\section{A Cascading Approach to Training Discovery}

4. A student is looking for a source to use in a paper on race and sentencing for her criminal justice class. List THREE resources you could use to start searching.

5. To search for sources on race and sentencing for her criminal justice class, what are some of the search terms that you would use?

6. A faculty member stops in to ask if we have access to the Journal of Sports Media online. Where can you go to find this information?
a. Online library catalog
b. EDS
c. Journal Finder
d. BrowZine
e. Databases A-Z

7. A student needs a journal article about housing affordability and families in Canada for her sociology project. Describe how you would assist this patron. (Where would you go to start searching? Which search terms would you use? Why?)

\section{Student Employee Training - Fall 2017 Research Challenge 2 questions}

1. A student approaches the desk and says he needs a book on politics in Iran for his comparative government class. Where is the best place to start your research?
a. Databases by Subject
b. EDS
c. Online library catalog
d. Google Scholar
e. Journal Finder 


\section{A Cascading Approach to Training Discovery}

2. A student wants to check out the book Legal aspects of health care administration. Do we own this book?

a. Yes, they can check out this book from the stacks

b. Yes, they can read it as an ebook

c. No, but a different university campus does own this book

d. No, they will need to request it from interlibrary loan

e. No, they will need to request it from the statewide circulation system

3. A student is looking for a book that is currently unavailable at our library because it is checked out. What is your next step to assist this student?

a. Use LMS to look up who currently has that book checked out.

b. Check the All Campuses box to see if they can request delivery from another university library.

c. Check the statewide circulation system to see if they can request it from another library in the state.

d. Place an interlibrary loan request so they can request it from another library.

4. A student needs help starting her research on nutrition and school lunches for her W131 research paper. Where is the best place to direct her to start her search?
a. Journal Finder
b. Online library catalog
c. EDS
d. Databases by Subject
e. Statewide circulation system

5. What are some search terms you would use to assist the student who is researching nutrition and school lunch? 


\section{A Cascading Approach to Training Discovery}

6. The student's paper is due tonight at midnight, so she needs articles she can access today. Which limiter in EDS will she need to select?
a. Peer Reviewed
b. Non-Print Resources
c. Full Text

7. What are some other limiters you could use to narrow down your search results for the student researching nutrition and school lunch?

8. A student needs newspaper articles from the 1980s about President Reagan's tax policies. Where can you start your search? (Check all that apply.)
a. Journal Finder
b. Online library catalog
c. Databases A-Z
d. Databases by Subject
e. BrowZine
f. $\operatorname{EDS}$

9. Pick one of the options you listed above and describe how you would assist this student. Make sure to provide: option chosen, search terms and limiters used, results received. 




Screenshot from EDS tutorial created and used by librarians at IU Bloomington

$429 \times 238 \mathrm{~mm}(96 \times 96 \mathrm{DPI})$ 